\title{
Assessment of Heavy Metal Pollution Using the Geo-accumulation Index (I-Geo), Pollution Load Index (PLI) and Potential Ecological Risk Index (RI) in Paddy Field Soils Adjacent to Ultrabasic Soils
}

\author{
${ }^{1}$ Waqeed Mahdi Hadif, ${ }^{2}$ Sahibin Abd Rahim, ${ }^{1}$ Ismail Sahid, ${ }^{1}$ Atiqur Rahman \\ and ${ }^{3}$ Izyanti Ibrahim \\ ${ }^{1}$ School of Environmental and Natural Resource Sciences, \\ ${ }^{3}$ School of Biosciences and Biotechnology, school of Science and Technology, \\ Universiti Kebangsaan Malaysia, 43600 Bangi, Selangor, Malaysia \\ ${ }^{2}$ Faculty of Science and Natural Resources, \\ Universiti Malaysia Sabah, 88400 Kota Kinabalu, Sabah, Malaysia \\ E-mail: waqeed@utq.edu.iq
}

\begin{abstract}
The content of heavy metals was appraised at paddy fields, from a total of 54 soil samples gathered from two locations in Ranau, Sabah and one from the UKM experimental paddy plot in Peninsular Malaysia, during2014 and 2015. Through an appraisal evaluate of contamination using the Index of Geo-accumulation (I geo) it was noted that Chromium and Nickel levels in Ranau field 1 came under grade 6 (I-geo $>5$ is considered to be very contaminated), showing that the soil was heavily tainted with $\mathrm{Cr}$ and $\mathrm{Ni}$, whilst Cobalt was discovered to be at the grade 3 level (medium to strong contamination). On the other hand, Ranau field 2's I-geo for other metals came under grade 1(which means medium to no contamination), highlighting the fact that the soils in these areas were tainted with the examined metals, while the control field was found to be grade 0 (no contamination). Ranau field 1 showed strong levels of the contamination factor (CF) for $\mathrm{Co}, \mathrm{Cr}$, and $\mathrm{Ni}$, and its Pollution Load Index was(PLI) was> 1, denoting a steady degradation in the area, with high levels of pollution compared to those in the other tested areas. The average monomial ecological risk for Ni was found to be between $(40-80)$, highlighting that $\mathrm{Ni}$ contamination was considered to be of medium danger to the surrounding environment. Through the Potential Ecological Risk Index, it was seen that Ni was a likely hazard and presented a substantial danger. The RI values for the test sites were as follows: season $2015(2.89)<$ control for season 2014 (3.18).
\end{abstract}

Keywords: Heavy Metal, Pollution, I-Geo, PLI, RI, Ultrabasic Soils. 


\section{Introduction}

A key characteristic of heavy metals which sets them apart from other toxic pollutants is that they do not degrade in the environment over time (Serife et al., 2003). A further related issue is the possibility of bioaccumulation or bio-magnifications, which can bring on stronger effects on organisms in that particular environment. Toxic metals build up in organisms because of the effects of the impact caused by their immediate environment. Even rainwater can act as a body for RDS in all directions, together with the numerous chemical components such as heavy metals, which lead to both surface and groundwater pollution. Certain soils found at the Ranau locations had high concentrations of heavy metals. Strong rainfall in the rainy season erodes the ultrabasic soil, which in turn flows into the Ranau Valley paddy fields through various irrigation pathways, and flooding streams. Ultrabasic soil contamination can be seen in the oily water and red colored earth in the paddies (Roslaili et al., 2015). Heavy metals and other pollutants impact the earth at the paddy fields and can be extremely harmful to living organisms in the stream. These contaminants impact the integrity of the paddy field soil and can be toxic to the flora of the stream, including the paddy plant, which will then cause the crop itself to be contaminated, thus affecting those who consume the tainted rice grains. An examination of the field soil will show the level of environmental impact from the heavy metals (Batley, 1989; Goorzadi et al., 2009). The index (I-geo) is a common approach to determine the level of soil pollution, as is the potential ecological risk index (RI) for the same purpose. In short, the I-geo is made up of 7 levels (Table 1), whilst the (RI) is made up of 5 levels (Table 2). This research was undertaken in order to calculate the heavy metal contamination present in the Ranau paddy soil (at two specific locations) and to compare this contamination with that of the control field soil, by the geo-accumulation index (I-Geo) and potential ecological risk index (RI). The aforementioned I-Geo in conjunction with the index of pollution load PLI and the potential ecological risk PI were used. This study aimed to evaluate the degree of contamination by heavy metals, using the index of geo-accumulation methodology and the Index of Pollution Load and to evaluate the risk of potential ecological posed by the heavy metals, with the aid of the potential ecological risk index methodology

\section{Location of the study areas.}

1- Ranau Field 1: located in the state of Sabah, Malaysia, adjacent to ultrabasic soil, Ranau field 1 recorded a very high concentration of heavy metal content indicating a contaminated area.

2- Ranau Field 2: located in Sabah, Malaysiaadjacent to Ultrabasic soil and also, contaminated with heavy metals.

3- Control field: The control field at UKM clearly shows lower heavy metal concentration indicating a non contaminated area. 


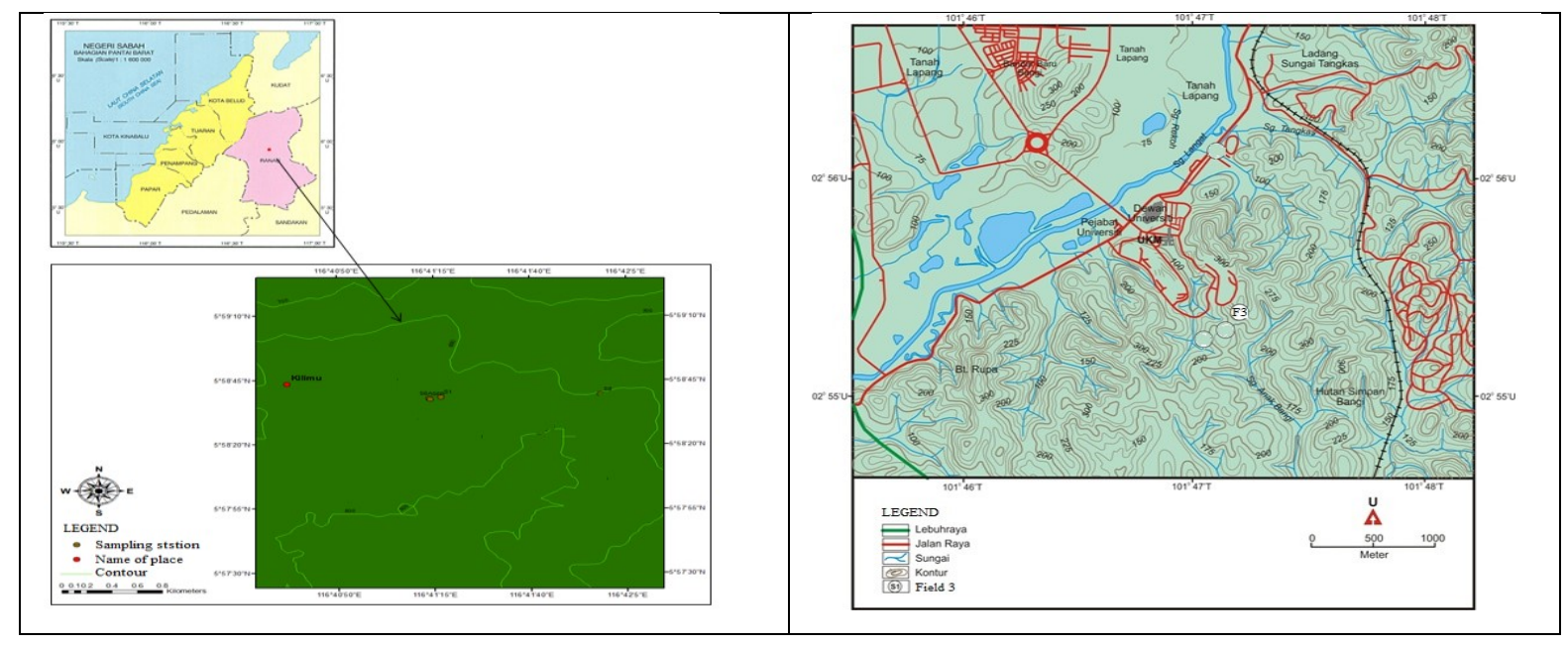

Figure 2 Location maps of the study area

\section{Material and Methods}

\section{Sample Collection \& Preparation}

The study was conducted at three paddy fields, two fields (field 1 and 2) near the ultrabasic soils located in Ranau, Sabah and one field (field 3) in Peninsular Malaysia. Ranau field 1 is approximately one kilometer away from field 2 and field 3, the control is located at the UKM experimental Paddy field plot in peninsular Malaysia. The experiment was conducted during the years 2014and 2015. Soil samples were obtained from a depth of thirty $\mathrm{cm}$. All soil samples were collected from the fields and then left to dry at ambient temperature. The dried soils were then pounding prior to sieving using a stainless steel sieve of pore size two millimeters for analysis of organic matter $(\mathrm{OM})$, particle size, $\mathrm{pH}$ soil $(\mathrm{pH})$, an electrical physical phenomenon (EC) and ion exchange capability (CEC). A nylon sieve of pore size $63 \mu \mathrm{m}$ was used to sieve the soil samples that were to be used for the analyses of the heavy metals. Methodologies adopted for individual studies are described in the relevant sections. It should be noted that all glass and plastic ware used were acid washed in $10 \% \mathrm{HNO} 3$ left overnight and were then washed 3 times with distilled deionized water, in order to avoid any risk of contamination. 


\section{University of Thi-Qar Journal of agricultural research}

ISSN Onlin:2708-9347, ISSN Print: 2708-9339 Volume 9, Issue 1 (2020) PP 85-97

https://jam.utq.edu.iq/index.php/main $\quad$ https://doi.org/10.54174/UTJagr.Vo9.N1/10

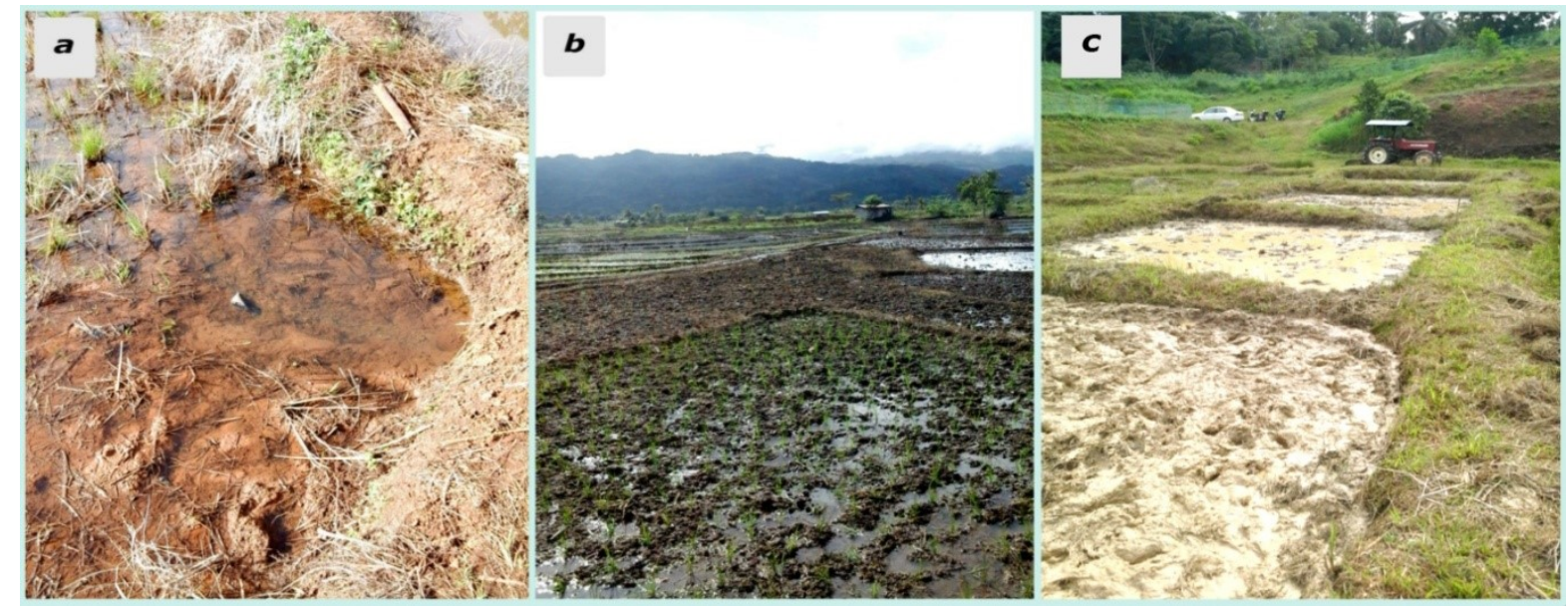

Figure 3 Experiment locations a) Ranau field 1, b), Ranau field 2, c), Control field.

\section{Heavy Metals Determination in the Soil Samples}

The samples were air dried, ground and sieved through a $63-\mu \mathrm{m}$ sieve. The wet digestion method was adopted to extract heavy metals from the soil samples (AOAC, 1984). One gram samples were weighed into conical flasks, then $15 \mathrm{~mL}$ of $\mathrm{HNO}_{3}$ was added followed by $5 \mathrm{~mL}$ of $\mathrm{HClO}_{4}(3: 1)$. The samples were then left to stand for $3 \mathrm{~h}$ in a sand bath, then the samples were filtered by using $0.45 \mu \mathrm{m}$ pore size Millipore filter paper and the volume adjusted to $50 \mathrm{~mL}$ with deionised water, prior to determination of the metal content using the ICPMass spectrometer model EIAN 9000. Heavy metals in the paddy plant parts were calculated according to the formula below:

M.C $\left(\mathrm{mg} / \mathrm{kg}^{-1}\right)=\left(\frac{\frac{\text { M.C in sample }\left(\frac{\mathrm{mg}}{\mathrm{mL}}\right) \times \text { Dillution factor }}{1000}-\frac{\text { M.C in blank }\left(\frac{\mathrm{mg}}{\mathrm{mL}}\right) \times \text { Dillution factor }}{1000}}{\frac{\text { Dry weight of sample }(\mathrm{gm})}{1000}}\right) \times \frac{\mathbf{5 0}}{1000}$

\section{Where:}

M.C $=$ Metal concentration

\section{The Index of Geo-Accumulation (I-geo)}

Established by Muller in 1969, the Index of Geo-accumulation (I-geo) was used to measure the metal build-up in the sediments, as it has been employed in a number of applications and research purposes. I-geo was calculated as follow: 
$\operatorname{Igeo}=\log 2(\mathrm{Cn} / 1.5 \mathrm{Bn})$

\section{Where:}

$\mathrm{Cn}=$ Element concentration in the soil sample

$\mathrm{Bn}=$ Value of geochemical background.

The factor 1.5 is used in the equation, in order to take into consideration the chance of disparities in background data because of lithogenic factors. The index of geo-accumulation (I-geo) scale is made up of seven levels $(0-6)$, from no contamination to heavy pollution (Table 1$)$.

Table 1 Geo-Accumulation Indexes showing pollution grades of Metals

\begin{tabular}{lll}
\hline Igeo class & Igeo value & RDS quality \\
\hline $\mathbf{0}$ & Igeo $\leq 0$ & uncontaminated \\
$\mathbf{1}$ & $0<$ Igeo $<1$ & uncontaminated to moderately contaminated \\
$\mathbf{2}$ & $1<$ Igeo $<2$ & moderately contaminated \\
$\mathbf{3}$ & $2<$ Igeo $<3$ & moderately to heavily contaminated \\
$\mathbf{4}$ & $3<$ Igeo $<4$ & heavily contaminated \\
$\mathbf{5}$ & $4<$ Igeo $<5$ & heavily to extremely contaminated \\
$\mathbf{6}$ & $5<$ Igeo & extremely contaminated \\
\hline
\end{tabular}

\section{The Index of Pollution Load (PLI).}

The Index of Pollution Load (PLI) is gathered as concentration Factors (CF), which are the quotient given by the division of the concentration of each metal. The concentration factor CF is made up of four levels $(0-3$, low to high CF) (Ahdy\& Khaled, 2009; Hakanson, 1980) (Table 2). The PLI of an area/location is estimated by gathering the n-root from the CFs of the metals found (Soares et al., 1999). The index of pollution load (PLI) was created by Tomlinson et al (1980) and is estimated as follows:

$\mathbf{C F}=\mathrm{C}$ metal $/ \mathrm{C}$ background value. 


\section{PLI $=n \sqrt{ }($ CF1 $1 \times C F 2 \times C F 3 x \ldots x C F n)$}

\section{Where:}

$\mathrm{CF}=$ contamination factor,

$\mathrm{n}=$ number of metals

$\mathrm{C}$ metal $=$ metal concentration in soil sample

$\mathrm{C}$ Background value $=$ background value of the metal.

Table 2 Contamination factor $(\mathrm{CF})$ index of metals

\begin{tabular}{lll}
\hline CF class & CF value & CF classification \\
\hline 0 & $\mathrm{CF}<1$ & low CF \\
1 & $1 \leq \mathrm{CF}<3$ & moderate $\mathrm{CF}$ \\
2 & $3 \leq \mathrm{CF}<6$ & considerable CF \\
3 & $\mathrm{CF} \geq 6$ & Very high $\mathrm{CF}$ \\
\hline
\end{tabular}

While a PLI value of 0 is 'Perfection', PLI=1 indicates baseline levels of pollutants in the examined sample, and PLI $>1$ denotes a steady increase of pollution in the specimen (Tomlinson et al., 1980; Harikumar et al., 2009). The global average concentrations for certain common heavy metals are (19 $\mu \mathrm{g} / \mathrm{g}), \mathrm{Cr}(90 \mu \mathrm{g} / \mathrm{g}), \mathrm{Cu}(45$ $\mu \mathrm{g} / \mathrm{g})$, Fe $(47200 \mu \mathrm{g} / \mathrm{g})$, Mn $(850 \mu \mathrm{g} / \mathrm{g})$, Ni $(68 \mu \mathrm{g} / \mathrm{g})$, and Zn $(95 \mu \mathrm{g} / \mathrm{g})$, as stated by Turekian \&Wedepohl (1961) and considered as the baseline figures.

The Index of Potential Ecological Risk (RI)

The Index of Potential Ecological Risk (RI) was initially discussed by Hakanson (1980) for assessing the heavy metal pollution in soil, depending on how the local environment was reacting and the level of metal toxicity. Through RI a thorough calculation of ecological risks brought on by toxic metals can be made using the equation below:

$F_{i}=C_{n}^{i} / C_{0}^{i}$

$\mathbf{E}_{\mathbf{r}}^{\mathrm{i}}=\mathbf{T}_{\mathbf{r}}^{\mathrm{i}} \times \mathbf{F}_{\mathbf{i}}$

$\mathbf{R I}=\sum \mathbf{E}_{\mathbf{r}}^{\mathbf{i}}$

\section{Where:}

$\mathrm{F}_{\mathrm{i}}=$ metal pollution index. 
$\mathrm{C}_{\mathrm{n}}^{\mathrm{i}}=$ metal concentration in the samples.

$\mathrm{C}_{\mathrm{o}}{ }^{\mathrm{i}}=$ metal reference value

$\mathrm{E}_{\mathrm{r}}^{\mathrm{i}}=$ factor of monomial potential ecological risk.

$\mathrm{T}_{\mathrm{r}}^{\mathrm{i}}=$ toxic response factor of metal (Hakanson 1980).

RI gives the possible ecological harm to the total pollution. Four categories exist for RI and five for $\mathrm{E}_{\mathrm{r}}^{\mathrm{i}}$, as presented in Table 3.

Table 3 Indices and Grades of Potential Ecological Risk caused by Toxic Metal Contamination

\begin{tabular}{llll}
\hline $\mathbf{E}_{\mathbf{r}}^{\mathbf{i}}$ value & Grades of ecological risk & RI value & $\begin{array}{l}\text { Grades } \\
\text { environment }\end{array}$ \\
\hline $\mathbf{E}_{\mathbf{r}}^{\mathbf{i}}<\mathbf{4 0}$ & low risk & $\mathrm{RI}<110$ & low risk \\
$\mathbf{4 0} \leq \mathbf{E}_{\mathbf{r}}^{\mathbf{i}}<\mathbf{8 0}$ & moderate risk & $110 \leq \mathrm{RI}<200$ & moderate risk \\
$\mathbf{8 0} \leq \mathbf{E}_{\mathbf{r}}^{\mathbf{i}}<\mathbf{1 6 0}$ & considerable risk & $200 \leq \mathrm{RI}<400$ & considerable risk \\
$\mathbf{1 6 0} \leq \mathbf{E}_{\mathbf{r}}^{\mathbf{i}}<\mathbf{3 2 0}$ & high risk & $400 \leq \mathrm{RI}$ & very high risk \\
$\mathbf{3 2 0} \leq \mathbf{E}_{\mathbf{r}}^{\mathbf{i}}$ & very high risk & & \\
\hline
\end{tabular}

\section{RESULTS AND DISCUSION}

\section{Heavy Metals Concentration in the Fields Soil}

The data revealed significant differences $(p<0.05)$ in heavy metal concentration among the different sites (Table 4). The Ranau fields were observed to have higher concentrations of all the heavy metals investigated, especially Ranau field 1 which recorded the highest concentration of all the metals studied for both seasons with values of 190.24, 4161.82, 87.24, 130050.12, 2228.59, 2639.60 and $148.89 \mathrm{mgkg}^{-1}$ in season 2014 and the values of $173.48,3374.85,59.55,97886.99,1962.64,2050.40$ and $133.64 \mathrm{mg} \mathrm{kg}^{-1}$ in season 2015 for the heavy metals $\mathrm{Co}, \mathrm{Cr}, \mathrm{Cu}, \mathrm{Fe}, \mathrm{Mn}, \mathrm{Ni}$ and $\mathrm{Zn}$ respectively. Higher concentration of all heavy metals were recorded in Ranau field 2 followed by that in the Ranau field 1 with values of 23.96, 312.51, 33.30, 27086.53, 393.14, 207.10 and $79.88 \mathrm{mg} \mathrm{kg}^{-1}$ in season 2014 and the values of $25.63,317.60,24.83,20634.84,406.60,186.79$ and $87.92 \mathrm{mgkg}^{-1}$ in season 2015 for the heavy metals $\mathrm{Co}, \mathrm{Cr}, \mathrm{Cu}, \mathrm{Fe}, \mathrm{Mn}, \mathrm{Ni}$ and $\mathrm{Zn}$ respectively. The control field recorded the minimum levels of heavy metals for both seasons with the values of $0.47,35.20,10.63,15827.07$, 
$50.10,6.07$ and $24.21 \mathrm{mg} \mathrm{kg}^{-1}$ in season 2014 and the values of $0.38,34.17,8.93,13552.92,57.27$, 5.76 and $25.00 \mathrm{mg} \mathrm{kg}^{-1}$ in season 2015 for $\mathrm{Co}, \mathrm{Cr}, \mathrm{Cu}, \mathrm{Fe}, \mathrm{Mn}, \mathrm{Ni}$ and $\mathrm{Zn}$, respectively.

Table 4 Mean Concentrations (mg.kg ${ }^{-1}$ dry weight) of Heavy Metals in the studied Soils Samples

\begin{tabular}{cllllllll}
\hline Seasons & Locations & $\boldsymbol{C o}$ & $\boldsymbol{C r}$ & $\boldsymbol{C u}$ & $\boldsymbol{F e}$ & $\boldsymbol{M n}$ & $\boldsymbol{N i}$ & $\boldsymbol{Z n}$ \\
\hline \multirow{0}{*}{} & \multirow{2}{*}{ Ranau field 1 } & 190.24 & 4161.82 & 87.24 & 130050.12 & 2228.59 & 2639.60 & 148.89 \\
& & \pm 17.17 & \pm 472.02 & \pm 7.21 & \pm 8754.34 & \pm 294.37 & \pm 183.56 & \pm 19.13 \\
& \multirow{2}{*}{ Ranau field 2 } & 23.96 & 312.51 & 33.30 & 27086.53 & 393.14 & 207.10 & 79.88 \\
& & \pm 2.89 & \pm 23.62 & \pm 1.73 & \pm 2134.11 & \pm 20.46 & \pm 16.23 & \pm 6.80 \\
& \multirow{2}{*}{ Control } & 0.47 & 35.20 & 10.63 & 15827.07 & 50.10 & 6.07 & 24.21 \\
& & \pm 0.02 & \pm 1.36 & \pm 0.72 & \pm 585.53 & \pm 1.73 & \pm 2.11 & \pm 12.30 \\
\hline \multirow{0}{*}{ Ranau field 1 } & 173.48 & 3374.85 & 59.55 & 97886.99 & 1962.64 & 2050.40 & 133.64 \\
& & \pm 36.05 & \pm 178.68 & \pm 0.60 & \pm 13340.74 & \pm 186.05 & \pm 228.36 & \pm 16.43 \\
& \multirow{2}{*}{ Ranau field 2 } & 25.63 & 317.60 & 24.83 & 20634.84 & 406.60 & 186.79 & 87.92 \\
& & \pm 2.42 & \pm 27.09 & \pm 0.86 & \pm 2093.25 & \pm 53.23 & \pm 15.01 & \pm 9.87 \\
& \multirow{2}{*}{ Control } & 0.38 & 34.17 & 8.93 & 13552.92 & 57.27 & 5.76 & 25.00 \\
& & \pm 0.08 & \pm 7.46 & \pm 0.42 & \pm 907.75 & \pm 4.80 & \pm 0.62 & \pm 2.57 \\
\hline
\end{tabular}

\section{Geo-accumulation index}

By using the index of geo-accumulation, it is possible to quantify the level of contamination in aquatic sediments (Singh et al., 2005). It is made up of seven levels, ranging from 'no pollution' up to 'very strong pollution'. Table 5 shows the index of geo-accumulation for the quantification of the examined location's heavy metal build-up. The I-geo grading for each metal was different at every test site. In the Ranau field 1 for 2014 and 2015, Chromium and Nickel were grade (6) an I-geo > 5, denotes extreme pollution from these two heavy metals. In addition, Cobalt in Ranau field 1 was graded as 3 in 2014, and at grade 2 in2015, describing medium to heavy pollution and medium pollution respectively. Other metals, including $\mathrm{Cu}, \mathrm{Fe}, \mathrm{Zn}$ and $\mathrm{Mn}$ for this location (as well as all metals at Ranau field 2) were at grade 1 (none to medium contamination) for 2014 and 2015, showing some level of pollution by these metals at the locations in general. On the other hand, the control field for both seasons was graded as 0 (no pollution) for all metals, showing that the test area soils were of a more average value with reference to the examined metals. The I-geo showed that all heavy metals at the Ranau field 2 and the control site were graded 0 and 1 respectively, showing that the soils there were of background levels and unaffected by human intervention. The levels of $\mathrm{Co}, \mathrm{Cr}, \mathrm{Cu}, \mathrm{Fe}, \mathrm{Mn}, \mathrm{Ni}$ and $\mathrm{Zn}$ at Ranau field 1, and $\mathrm{Co}, \mathrm{Cr}$ and $\mathrm{Ni}$ at Ranau field 2 were higher than average for both the seasons. This could be due to the degradation of the Ultrabasic soil due to strong rainfall in the rainy season, and the subsequent flow 
of these metals at Ranau paddy fields through irrigation systems and flooding streams, or from other agricultural operations in the area (Aziz, Rahim et al., 2015).

Table 5 Geo-accumulation index for the studied heavy metals at the test locations.

\begin{tabular}{rllllllll}
\hline Seasons & Locations & $\boldsymbol{C o}$ & $\boldsymbol{C r}$ & $\boldsymbol{C u}$ & $\boldsymbol{F e}$ & $\boldsymbol{M n}$ & $\boldsymbol{N i}$ & $\boldsymbol{Z n}$ \\
\hline \multirow{2}{*}{$\mathbf{A}$} & Ranau field 1 & 2.01 & 9.28 & 0.39 & 0.55 & 0.53 & 7.79 & 0.31 \\
& Ranau field 2 & 0.25 & 0.70 & 0.15 & 0.12 & 0.09 & 0.61 & 0.17 \\
& Control & 0.00 & 0.08 & 0.05 & 0.07 & 0.01 & 0.02 & 0.05 \\
\hline \multirow{2}{*}{$\boldsymbol{u}$} & Ranau field 1 & 1.83 & 7.52 & 0.27 & 0.42 & 0.46 & 6.05 & 0.28 \\
& Ranau field 2 & 0.27 & 0.71 & 0.11 & 0.09 & 0.10 & 0.55 & 0.19 \\
& Control & 0.00 & 0.08 & 0.04 & 0.06 & 0.01 & 0.02 & 0.05 \\
\hline
\end{tabular}

\section{Pollution load index}

The severity of the contamination at the three locations was established through the pollution load index, which is an easy way to compare levels of pollution at a number of locations simultaneously at once (Adebowale et al., 2009). The outcome of the present paper denotes that the CF levels for $\mathrm{Co}, \mathrm{Cr}$ and $\mathrm{Ni}$ at Ranau field 1 were of class $3(\mathrm{CF}>6)$ for both seasons (Table (6). This showed extremely high CF, possibly because of the impact of erosion of the Ultrabasic soil, whilst the rest metals like $\mathrm{Cu}, \mathrm{Fe}, \mathrm{Mn}$ and $\mathrm{Zn}$ were of class $1(1-3)$, indicating medium levels of CF. Also, the CF of Ranau field 2 for Cr and Ni were of class $2(3-6)$, highlighting a stronger level of CF, especially compared to the low CF of the other metals in the same location and in the control field, which were graded under class $0(\mathrm{CF}<1)$. Furthermore, the Pollution Load Index (Table 7) was more than 1 (PLI > 1) in most cases at the Ranau field 1, for both seasons, indicating strong levels of degradation and contamination. On the other hand, the CF for Ranau field 2 showed much lower levels and was more comparable to the control field for both seasons, recording baseline levels of pollutants.. The disparity of the methodology for these measurement is the likely cause because of varying sensitivity of these indices to the metals under observation (Praveena et al., 2007).

Table 6 Contamination factor for metals at all the studied locations

\begin{tabular}{|c|c|c|c|c|c|c|c|c|}
\hline Seasons & Locations & CF Co & $C F C r$ & $C F C u$ & CF Fe & $C F M n$ & $C F \mathrm{Ni}$ & $\overline{C F Z n}$ \\
\hline \multirow{3}{*}{ 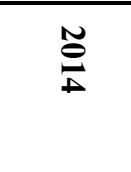 } & Ranau field 1 & 10.01 & 46.24 & 1.94 & 2.76 & 2.62 & 38.82 & 1.57 \\
\hline & Ranau field 2 & 1.26 & 3.47 & 0.74 & 0.57 & 0.46 & 3.05 & 0.84 \\
\hline & Control & 0.02 & 0.39 & 0.24 & 0.34 & 0.06 & 0.09 & 0.25 \\
\hline \multirow{2}{*}{$\underset{\Theta}{\stackrel{N}{\Theta}}$} & Ranau field 1 & 9.13 & 37.50 & 1.32 & 2.07 & 2.31 & 30.15 & 1.41 \\
\hline & Ranau field 2 & 1.35 & 3.53 & 0.55 & 0.44 & 0.48 & 2.75 & 0.93 \\
\hline
\end{tabular}




\begin{tabular}{rlllllll}
\hline Control & 0.02 & 0.38 & 0.20 & 0.29 & 0.07 & 0.08 & 0.26 \\
\hline
\end{tabular}

Table 7 Pollution load index (PLI) of locations

\begin{tabular}{|c|c|c|c|}
\hline Seasons & Locations & $P L I$ & Description \\
\hline \multirow{3}{*}{$\stackrel{\widetilde{\sigma}}{\stackrel{\oplus}{\Phi}}$} & Ranau field 1 & 6.30 & polluted \\
\hline & Ranau field 2 & 1.12 & polluted \\
\hline & Control & 0.14 & no polluted \\
\hline \multirow{3}{*}{$\stackrel{N}{\stackrel{v}{u}}$} & Ranau field 1 & 5.12 & polluted \\
\hline & Ranau field 2 & 1.05 & polluted \\
\hline & Control & 0.13 & no polluted \\
\hline
\end{tabular}

\section{Potential Ecological Risk Index (RI)}

Table 8 presents an overview of the outcome of the collected ecological risk assessment for the toxic metals in the selected soil samples. It was seen that the average monomial risk factors $\left(\mathrm{E}_{\mathrm{r}}^{\mathrm{i}}\right)$ for the metals in the soil samples were as follows: $\mathrm{Zn}<\mathrm{Mn}<\mathrm{Fe}<\mathrm{Cu}<\mathrm{Co}<\mathrm{Cr}<\mathrm{Ni}$. Furthermore, the average monomial ecological risk for $\mathrm{Ni}$ was $(40-80)$, highlighting the fact that $\mathrm{Ni}$ was of medium danger to the immediate environment. On the other hand, the Ni level at Ranau field 1 ranged from160 - 320 for the 2014 season and $80-160$ in the 2015 season, showing that $\mathrm{Ni}$ was extremely hazardous and very hazardous for the area in 2014 and 2015 respectively. The mean $\mathrm{E}_{\mathrm{r}}^{\mathrm{i}}$ levels for the other metals observed showed Cr level under 40, highlighting its limited potential effect on the local ecosystems. Elsewhere, the only noteworthy monomial ecological risk of over 160 was 194.09 at the Ranau field 1 during the 2014 season, denoting strong risk. In addition, the $\mathrm{E}_{\mathrm{r}}^{\mathrm{i}}$ for $\mathrm{Cr}$ in 2014 was 92.48 and for $\mathrm{Ni}$ in 2015 was 150.76 at the Ranau field 1 location, highlighting significant pollution (as with any levels over 80). The $\mathrm{E}_{\mathrm{r}}^{\mathrm{i}}$ value for Co in the Ranau field 1 across both seasons was 50.06 and 45.65 respectively, thus falling between the 40-80 range and denoting medium risk, while the $\mathrm{E}_{\mathrm{r}}^{\mathrm{i}}$ levels for other metals across all test sites were under 40, denoting limited risk. To assess the total possible ecological risk of the examined metals in the paddy field soil, RI was estimated as the total of all the seven risk factors (seen in Table 8). RI levels for the test sites were as follows: control in season $2015(2.89)<$ control in season 2014 (3.18) <Ranau field 2 in season 2015 (32.14) < Ranau field 2 in season 2014 (34.06) < Ranau field 1 in season 2015 (283.82) <Ranau field 1 in season 2014 (353.27). It can be seen that heavy metals contamination at Ranau field 1 was of substantial risk, whereas metals were of low risk to the immediate environment at 
Ranau field 2 and the control site, across both seasons. RI is able to describe the sensitivity of the local ecosystems with regards to the heavy (toxic) metals examined, and show the levels of ecological danger brought on by the levels of pollution. The overall ecological hazards in the Ranau field 1 location were : Co 14.17\%, Cr 26.18\%, Cu 2.74\%, Fe 0.78\%, Mn 0.74\%, Ni 54.94\% and $\mathrm{Zn} \mathrm{0.44 \%} \mathrm{in} \mathrm{season} \mathrm{2014,} \mathrm{and} \mathrm{Co}$ 16.09\%, Cr 26.42\%, CU 2.33\%, Fe 0.73\%, Mn 0.81\%, Ni 53.12\% and Zn 0.50\% in season 2015. In total, Cr and $\mathrm{Ni}$ were responsible for (25.80 and 52.82) respectively of the overall potential ecological risk of the Ranau field 1 location. The Geo-accumulation appraisal showed that $\mathrm{Cr}$ and $\mathrm{Ni}$ were mostly of the very high pollution level, and so the ecological risk arising from these metals was significant because of the high toxicity in comparison to Fe and $\mathrm{Zn}$ (which had lesser levels of toxicity). As a result, it can be seen that the I-geo method is primarily aimed at the levels of build-up for individual metals, without taking into account the toxic response factor. On the other hand, the Potential Eco-logical Risk Index denotes the ecological dangers by specific contaminants as well as the risks associated by a combination of a number of pollutants (Hakanson, 1980).

Table 8 The Heavy Metal Potential Ecological Risk Indexes in locations

\begin{tabular}{|c|c|c|c|c|c|c|c|c|c|c|}
\hline \multirow{2}{*}{ Season } & \multirow{2}{*}{ Locations } & \multicolumn{7}{|l|}{$\overline{\mathbf{E}_{\mathrm{i}}}$} & \multirow{2}{*}{ RI } & \multirow{2}{*}{$\begin{array}{l}\text { Pollution } \\
\text { degree }\end{array}$} \\
\hline & & Co & $\overline{C r}$ & $C u$ & $F e$ & $M n$ & $\overline{N i}$ & $Z n$ & & \\
\hline \multirow[t]{3}{*}{$\stackrel{\sim}{\ominus}$} & Ranau field 1 & 50.06 & 92.48 & 9.69 & 2.76 & 2.62 & 194.09 & 1.57 & 353.27 & $\begin{array}{l}\text { considerable } \\
\text { risk }\end{array}$ \\
\hline & Ranau field 2 & 6.31 & 6.94 & 3.70 & 0.57 & 0.46 & 15.23 & 0.84 & 34.06 & low risk \\
\hline & Control & 0.12 & 0.78 & 1.18 & 0.34 & 0.06 & 0.45 & 0.25 & 3.18 & low risk \\
\hline \multirow[t]{3}{*}{ 气̃ } & Ranau field 1 & 45.65 & 75.00 & 6.62 & 2.07 & 2.31 & 150.76 & 1.41 & 283.82 & $\begin{array}{l}\text { considerable } \\
\text { risk }\end{array}$ \\
\hline & Ranau field 2 & 6.74 & 7.06 & 2.76 & 0.44 & 0.48 & 13.73 & 0.93 & 32.14 & low risk \\
\hline & Control & 0.10 & 0.76 & 0.99 & 0.29 & 0.07 & 0.42 & 0.26 & 2.89 & low risk \\
\hline
\end{tabular}

\section{Conclusion}

Pollution measurement through the Index of Geo-accumulation (I geo) highlighted that Chromium and Nickel at the Ranau field 1 location were of extreme contaminations levels, while other heavy metals at the same site 
as well as all metals at the Ranau field 2 site were of grade 1 (no contamination to medium contamination), showing limited levels of pollution from these metals. The Pollution Load Index denoted that at the Ranau field 1 site, there was a steady degradation and definite pollution compared to that at the other locations, as PLI $>1$. Through the Index of Potential Ecological Risk, Ni was shown as being of high risk as well as of moderate risk. Cr and Ni were accountable for (25.80 and 52.82) respectively of the overall potential ecological risk at Ranau field 1. The outcome of the ecological risk evaluation demonstrated that $\mathrm{Cr}$ and Ni were the metals with the highest possible risk to the local ecosystems. In summary, the risk indices showed that the Ranau field 1 site was graded as a higher class of risk compared to that of the other two tested locations.

\section{Acknowledgment}

This research was supported by the research grant FRGS/2/2013/STWN01/UKM/01/2. The authors thank the Faculty of Science and Technology and The National University of Malaysia for providing the research facilities for undertaking the project.

\section{REFERENCES}

1. Adebowale, K. O., Agunbide, F. O., \& Olu-Owolabi, B. (2009). Trace metal concentration, site variations and partitioning pattern in water and bottom sediments from coastal area: A case study of Ondo Coast, Nigeria. Environmental Research Journal, 3(2), 46-59.

2. Ahdy, H. H., \& Khaled, A. (2009). Heavy metals contamination in sediments of the western part of Egyptian Mediterranean Sea. Australian Journal of Basic and Applied Sciences, 3(4), 3330-3336.

3. AOAC. Official Method of Analysis. 14th Edn. Sidney William. Association of Official Chemists, Inc. Virginia, USA. 1984.

4. Aziz, R. A., et al. (2015). "Determination of Heavy Metals Uptake in Soil and Paddy Plants." American-Eurasian J. Agric. \& Environ. Sci., 15 (2): 161-164, 2015.

5. Batley, G. E. (1989). Trace Element Speciation Analytical Methods and Problems. CRC Press.

6. Goorzadi, M., Vahabzadeh, G., Ghanbarpour, M. R., \& Karbassi, A. R. (2009). Assessment of heavy metal pollution in Tilehbon River sediments, Iran. Journal of applied sciences, 9(6), 1190-1193.

7. Hakanson, L. L., 1980, "An ecological risk index aquatic pollution control, a sedimentological approach”, Water Re-search, 14 (8), 975 - 1001. 
8. Harikumar, P. S., Nasir, U. P., \& Rahman, M. M. (2009). Distribution of heavy metals in the core sediments of a tropical wetland system. International Journal of Environmental Science \& Technology, 6(2), 225-232.

9. Muller, G., 1969, "Index of geo-accumulation in sediments of Rhine River", Geochemical Journal, 2, $108-118$.

10. Praveena, S. M., Radojevic, M., \& Abdullah, M. H. (2007). The Assessment of Mangrove Sediment Quality in Mengkabong Lagoon: An Index Analysis Approach. International Journal of Environmental and Science Education, 2(3), 60-68.

11. Serife, T., Senol, K., and Gokhan, B., 2003, "Comparison of three sequential extraction procedure for portioning of heavy metals in car park dust", Journal of Environmental Monitor-ing, 5, $468-476$.

12. Singh, V. K., Singh, K. P., \& Mohan, D. (2005). Status of heavy metals in water and bed sediments of river Gomti-A tributary of the Ganga river, India. Environmental monitoring and assessment, 105(1-3), 43-67.

13. Soares, H. M. V. M., Boaventura, R. A. R., Machado, A. A. S. C., \& Da Silva, J. E. (1999). Sediments as monitors of heavy metal contamination in the Ave river basin (Portugal): multivariate analysis of data. Environmental Pollution, 105(3), 311-323.

14. Tomlinson, D. L., Wilson, J. G., Harris, C. R., \& Jeffrey, D. W. (1980). Problems in the assessment of heavy-metal levels in estuaries and the formation of a pollution index. Helgoländer Meeresuntersuchungen, 33(1-4), 566-575.

15. Turekian, K. K., \& Wedepohl, K. H. (1961). Distribution of the elements in some major units of the earth's crust. Geological Society of America Bulletin, 72(2), 175192. 